\title{
Change features of time-series climate variables from 1962 to 2016 in Inner Mongolia, China
}

\author{
XU Lili ${ }^{1,2^{*}}$, YU Guangming ${ }^{1,2}$, ZHANG Wenjie ${ }^{3,4}$, TU Zhenfa ${ }^{1,2}$, TAN Wenxia ${ }^{1,2}$ \\ ${ }^{1}$ Key Laboratory for Geographical Process Analysis \& Simulation of Hubei Province, Central China Normal University, \\ Wuhan 430079, China; \\ ${ }^{2}$ College of Urban and Environmental Sciences, Central China Normal University, Wuhan 430079, China; \\ ${ }^{3}$ State Key Laboratory of Resources and Environmental Information System, Institute of Geographic Sciences and Natural \\ Resources Research, Beijing 100101, China; \\ ${ }^{4}$ Plant Functional Biology and Climate Change Cluster (C3), University of Technology Sydney, NSW 2007, Australia
}

\begin{abstract}
Detecting change features of climate variables in arid/semi-arid areas is essential for understanding related climate change patterns and the driving and evolution mechanism between climate and arid/semi-arid ecosystems. This paper takes Inner Mongolia of China, a unique arid/semi-arid ecosystem, as the study area. We first detected trend features of climate variables using the linear trend analysis method and then detected their trend-shift features using the breaks for additive seasonal and trend method based on the time-series of monthly precipitation and monthly mean temperature datasets from 1962 to 2016. We analyzed the different change features of precipitation and temperature on a regional scale and in different ecological zones to discover the spatial heterogeneity of change features. The results showed that Inner Mongolia has become warmer-wetter during the past 54 years. The regional annual mean temperature increased $0.4^{\circ} \mathrm{C}$ per decade with a change rate of $56.2 \%$. The regional annual precipitation increased $0.07 \mathrm{~mm}$ per decade with a slightly change rate of about $1.7 \%$, but the trend was not statistically significant. The warmer trend was contributed by the same positive trend in each season, while the wetter trend was contributed by the negative trend of the summer precipitation and the positive trend of the other three seasons. The regional monthly precipitation series had a trend-shift pattern with a structural breakpoint in the year 1999, while the regional monthly mean temperature series showed an increasing trend without a periodical trend-shift. After the year 2000, the warmer-wetter trend of the climate in Inner Mongolia was accelerated. The late $20^{\text {th }}$ century was a key period, because the acceleration of the wetter trend in some local zones (I and II) and the alleviation of the warmer trend in some local zones (VII, VIII and IX) occurred simultaneously. Moreover, the change features had a strong spatial heterogeneity, the southeastern and southwestern of Inner Mongolia went through a warmer-drier trend compared with the other areas. The spatio-temporal heterogeneity of the climate change features is a necessary background for various types of research, such as regional climate change, the evolution of arid/semi-arid ecosystems, and the interaction mechanisms between climate and arid/semi-arid ecosystems based on earth-system models in Inner Mongolia.
\end{abstract}

Keywords: temperature; precipitation; trend feature; trend-shift feature; arid/semi-arid area

Citation: XU Lili, YU Guangming, ZHANG Wenjie, TU Zhenfa, TAN Wenxia. 2020. Change features of time-series climate variables from 1962 to 2016 in Inner Mongolia, China. Journal of Arid Land, 12(1): 58-72. https://doi.org/10.1007/s40333-0190124-4

\footnotetext{
*Corresponding author: XU Lili (E-mail: xulls@mail.ccnu.edu.cn)

Received 2018-04-08; revised 2019-08-09; accepted 2019-10-17

(C) Xinjiang Institute of Ecology and Geography, Chinese Academy of Sciences, Science Press and Springer-Verlag GmbH Germany, part of Springer Nature 2020
} 


\section{Introduction}

Climate change is one of the most important issues in global change research (Mahoney et al., 2004). The fifth "Intergovernmental Panel on Climate Change" report claimed that the global mean surface temperature has increased since the late $19^{\text {th }}$ century, with a warming of $0.72^{\circ} \mathrm{C}\left(0.49^{\circ} \mathrm{C}\right.$ to $0.89^{\circ} \mathrm{C}$ ) over the period 1951-2012 (Hartmann et al., 2013). It has predicted by several studies that severe storms and heatwaves prolonged drought and raised sea levels in the near future (Charles, 2012; Dufresne et al., 2013; Leng et al., 2015; Mora et al., 2017) could dramatically influence the habitats of all life on the planet (Mora et al., 2017). Climate variables are the key parameters in many models based on the earth-atmosphere system. Accurately analyzing the change features of climate variables is not only essential for monitoring and forecasting climate change but also important for the sustainable development of terrestrial ecosystems.

Arid/semi-arid ecosystems around the globe are especially fragile and extremely sensitive to external interference, such as climate change (Maestre and Cortina, 2002; Chen et al., 2012; Han et al., 2015; Zhang et al., 2016). Recent evidence has shown that dry lands would expand all over the world (Huang et al., 2016) and suffer more from the influence of climate change compared with humid areas (Huang et al., 2017). Therefore, it is a pressing need to improve the understanding of the global climate change and the interaction mechanisms between climate and arid/semi-arid ecosystems (Hu et al., 2015; Huang et al., 2015a, b; Wang et al., 2017).

In northern and western China, arid/semi-arid areas are widely distributed and cover one-third of the Chinese land area. Inner Mongolia, an especially sensitive region in China, has one of the most unique arid/semi-arid ecosystems (Peng et al., 2013; Liu et al., 2018). Because of global climate change and rapid economic growth during the past decades, the regional ecosystem has changed greatly (Xu et al., 2016). The Chinese government has launched several ecological restoration programs in this area since 2000 (Chen et al., 2017; Shao et al., 2017), such as the "Three-North Shelterbelt Project", the "Grain for Green Project" and the "Beijing-Tianjin Sand Source Control Project", which have greatly influenced the relationship between humans and nature. Therefore, the Inner Mongolia of China has become one of the most attractive areas for the studies about arid/semi-arid ecosystem (Chen et al., 2013; Hu et al., 2015; Huang et al., 2015b; Zhang et al., 2018), such as climate change analysis (Peng et al., 2013), climate-vegetation relationship analysis (Bhandari et al., 2015; Tong et al., 2017) and land cover change (Guo et al., 2014).

Precipitation and temperature are two key climate variables controlling arid/semi-arid vegetation growth (Bao et al., 2010; You et al., 2010; Peng et al., 2013; An, 2015). They are also important parameters for the calculation of various arid indices (Huang et al., 2016) and for the construction of earth-atmosphere models (Fisher et al., 2017). Therefore, it is crucial to detect the detailed and accurate change features of the time-series of precipitation and temperature datasets in Inner Mongolia. Previous studies mainly focused on the overall trend analysis of these two variables and contrary results were found in different studies, e.g., Hu et al. (2015) found that Inner Mongolia became warmer-drier from 1961 to 2012, while others demonstrated a warmer-wetter trend (Geng et al., 2016; Hu et al., 2017; Qin et al., 2018). Meanwhile, the trend-shift features in the time-series of precipitation and temperature in Inner Mongolia are interesting but have rarely been analyzed. $\mathrm{Hu}$ et al. (2015) found that the increasing trend in global temperature has slowed down since the late 1990s. It was unknown whether temperature change in Inner Mongolia reflected the same pattern. Hu et al. (2017) also found a nonlinear change in precipitation in Inner Mongolia through observing the time-series change trajectory. The detection of climate trend-shift features in Inner Mongolia could not only reveal the detailed change patterns from an apparently consistent trend line, but also elucidate the coupled and response relationship between climate and arid/semi-arid ecosystems. It has been confirmed that there is a nonlinear relationship between climate variables and vegetation cover in arid/semi-arid ecosystems (Wu et al., 2017; Harrison et al., 2018). The detection of detailed and accurate change features, especially the nonlinear change features within a time-series of precipitation and temperature, is useful for understanding the nonlinear relationships between climate variables and vegetation ecosystems in Inner Mongolia. 
This study aims to detect trend and trend-shift features in precipitation and temperature over the period 1962-2016 in Inner Mongolia, China. The features are closely related to vegetation growth in arid/semi-arid ecosystems. We detect the overall trend in time-series of annual precipitation and annual mean temperature datasets, and then detect the decade-scale trend-shift features in monthly precipitation and monthly mean temperature datasets. We also analyze the change features in different seasons and ecological zones to further describe the temporal-spatial heterogeneity of the change features on a local scale. Our results could help to understand the local detailed change mechanisms of key climate variables, and then to provide basic background knowledge to research on the relationship between climate and arid/semi-arid ecosystems in the local study areas.

\section{Materials and methods}

\subsection{Study area}

The Inner Mongolia Autonomous Region of China $\left(37^{\circ} 24^{\prime}-53^{\circ} 23^{\prime} \mathrm{N}, 97^{\circ} 12^{\prime}-126^{\circ} 04^{\prime} \mathrm{E}\right)$, with an area of about $1.18 \times 10^{6} \mathrm{~km}^{2}$, was chosen as the study area (Fig. 1). The mean annual precipitation varies from $50 \mathrm{~mm}$ in the northwest to $500 \mathrm{~mm}$ in the northeast while the annual mean temperature varies from $0^{\circ} \mathrm{C}$ to $8^{\circ} \mathrm{C}$. Humid, semi-arid and arid zones are found from east to west. Soil types are black soil, chernozem, chestnut soil and sandy soil. Vegetation comprises forest, steppe and desert steppe (Hu et al., 2015).

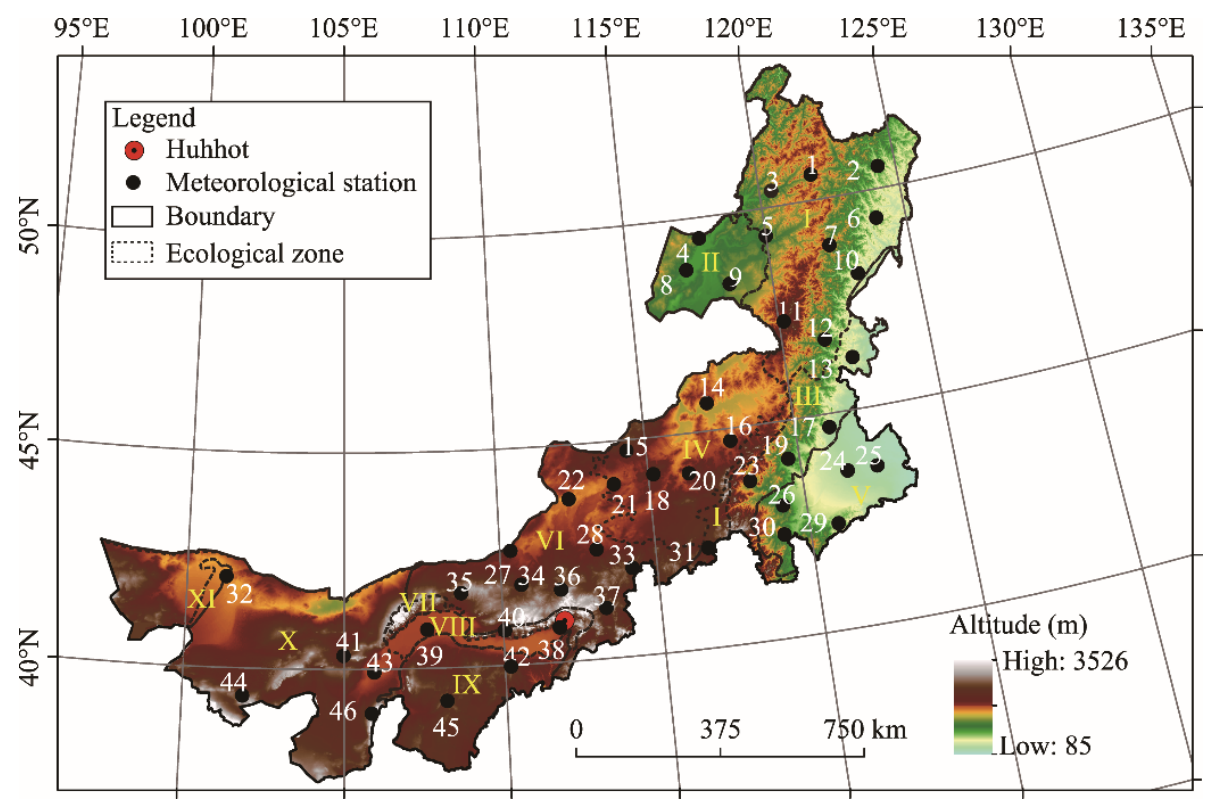

Fig. 1 Distributions of the 11 ecological zones (I-XI) and the 46 meteorological stations (1-46)

\subsection{Data}

In this study, monthly precipitation and monthly mean temperature datasets were acquired from the website of the China Meteorological Data Service Center (http://data.cma.cn/). The datasets contain records of 46 meteorological stations located in the study area (Fig. 1) for the period from January 1962 to May 2016 and the quality of the datasets was tested, showing no erroneous data. The missing data at the beginning or end of the time-series were replaced by the average values of those months in all the other years, while the remaining missing data were filled using the linear interpolation method (Hu et al., 2015). The missing data, overall, comprised less than $0.08 \%$ of all datasets. In each meteorological station, there are 653 points within each monthly precipitation and monthly mean temperature series. All the 653 points were used in analyzing decade-scale trendshift features based on the breaks for additive season and trend (BFAST) method. Monthly mean temperature series were reconstructed to annual mean temperature series with 54 points from 1962 
to 2015 by averaging the monthly values within each year. Monthly precipitation series were reconstructed to annual precipitation series with 54 points from 1962 to 2015 by the accumulated monthly values within each year. The annual mean series were used to analysis the overall trend based on linear trend detection method. The data in 2016 were not involved in reconstructing the annual mean series because there were not enough samples in this year. The series of different seasons were reconstructed by accumulating the value of different months within each year, i.e., spring (March to May), summer (June to August), autumn (September to November) and winter (December to February in the next year). These seasonal accumulated time series temperature and precipitation datasets were used to analysis seasonal trend features.

The natural environment of Inner Mongolia has a strong spatial heterogeneity. The spatial heterogeneity analysis was based on a 1:5,000,000 ecological zone map of Inner Mongolia. The study area is divided into 11 ecological zones (Table 1; Fig. 1) according to climate, soil, landform and vegetation conditions (Xu et al., 2016). As the distributions of meteorological stations in the zones of VII and VIII are sparse and uneven, we merged these two small neighboring zones into one.

Table 1 Meteorological stations in different ecological zones

\begin{tabular}{|c|c|c|c|c|}
\hline \multirow{2}{*}{$\begin{array}{l}\text { Ecological } \\
\text { zone }\end{array}$} & \multirow{2}{*}{ Areas } & \multicolumn{2}{|c|}{ Characteristic } & \multirow{2}{*}{$\begin{array}{l}\text { Meteorological } \\
\text { station code }\end{array}$} \\
\hline & & Landscape & Vegetation & \\
\hline I & Da Hinggan Mountains & Grassland & Quercus mongolica & $\begin{array}{c}1,2,3,6,7,10,11 \\
12,31\end{array}$ \\
\hline II & Hulun Buir Plateau & $\begin{array}{l}\text { Central Mongolian Plateau, } \\
\text { steppe }\end{array}$ & $\begin{array}{c}\text { Stipa krylovii, } \\
\text { Cleistogenes } \\
\text { caespitosa }\end{array}$ & $4,5,8,9$ \\
\hline III & Songliao Plain & Grassland & Ulmus pumila & $13,17,19,23$ \\
\hline IV & Xilingol Plateau & $\begin{array}{l}\text { Hunshandak sandy land, } \\
\text { grassland }\end{array}$ & Ulmus pumila & $14,15,16,18,20$ \\
\hline V & West Liaohe River Plain & $\begin{array}{l}\text { Alluvial plain, irrigated } \\
\text { agricultural area }\end{array}$ & Crops: corn and wheat & $24,25,26,29,30$ \\
\hline VI & Ulanqab Plateau & Red sand, steppe desert & Stipa glareosa & $\begin{array}{r}21,22,27,28,33 \\
34,35,36,37\end{array}$ \\
\hline VII\&VIII & $\begin{array}{c}\text { Yinshan Mountains, } \\
\text { Hetao-Tumochuan } \\
\text { Plain }\end{array}$ & $\begin{array}{l}\text { Alluvial plain, irrigated } \\
\text { agricultural area, steppe }\end{array}$ & $\begin{array}{c}\text { Crops: wheat, rice and } \\
\text { cereal }\end{array}$ & $38,39,40$ \\
\hline IX & Ordos Plateau & Steppe desert & Cistus ladanifer & 42,45 \\
\hline $\mathrm{X}$ & $\begin{array}{c}\text { Bayannur-Alagxa High } \\
\text { Plain }\end{array}$ & Gobi, desert & Ephedra & $41,43,44,46$ \\
\hline $\mathrm{XI}$ & $\begin{array}{c}\text { Lower reaches of Heihe } \\
\text { River Oasis }\end{array}$ & Alluvial plain, oasis & $\begin{array}{l}\text { Populus diversifolia } \\
\text { forest }\end{array}$ & 32 \\
\hline
\end{tabular}

\subsection{Methodologies}

We first detected the trend feature of climate variables based on the time-series of annual precipitation and annual mean temperature datasets with 54 points, then detected the trend-shift features of climate variables based on the time-series with 653 points. The above detection processes were first conducted on a regional scale and then in different ecological zones to discover the spatial heterogeneity of the change features of precipitation and temperature.

\subsubsection{Detection of trend features}

The linear regression detection method ( $\mathrm{Hu}$ et al., 2015) was used to determine the trend of each climate variable $(\alpha=0.05)$. The trend slope can be defined by the least-squares estimation method as in Equation 1:

$$
\text { Slope }=\frac{\sum_{i=1}^{n} x_{i} y_{i}-\frac{1}{n}\left(\sum_{i=1}^{n} x_{i}\right)\left(\sum_{i=1}^{n} y_{i}\right)}{\sum_{i=1}^{n} x_{i}^{2}-\frac{1}{n}\left(\sum_{i=1}^{n} x_{i}\right)^{2}},
$$

where Slope is the trend slope of the time-series, with Slope $>0$ means a positive trend and Slope $<0$ 
means a negative trend; $n$ is the number of years $(n=54) ; x_{i}$ is the value of the independent variable (i.e., years); and $y_{i}$ is the value of the dependent variable (i.e., annual mean temperature series and annual precipitation series) in the $i^{\text {th }}$ year.

The significance of Slope can be determined using the $F$-test as in Equations 2-4:

$$
\begin{gathered}
F=\frac{U}{\mathrm{Q} /(n-2)}, \\
Q=\sum_{i=1}^{n}\left(y_{i}-\bar{y}\right)^{2}, \\
U=\operatorname{Slope}^{2} \times \sum_{i=1}^{n}\left(x_{i}-\bar{x}\right)^{2},
\end{gathered}
$$

where $U$ is the sum of squares due to regression; $Q$ is the sum of squares due to error; $\bar{x}$ is the mean value of the independent variable; and $\bar{y}$ is the mean value of the dependent variable (i.e., annual precipitation series and annual mean temperature series). The change rate of dependent variable over the study period, which directly expresses the magnitude of the trend change, can be determined using Equations 5 and 6:

$$
\begin{gathered}
\text { Rate }=\left|\frac{\left(\text { Slope } \times x_{n}+a\right)-\left(\text { Slope } \times x_{1}+a\right)}{\begin{array}{l}
\text { Slope } \times x_{1}+a \\
a=\bar{y}-\text { Slope } \times \bar{x},
\end{array}}\right| \times 100, \\
\text { S }
\end{gathered}
$$

where Rate is the rate of change; $a$ is the intercept of regression equation; and $x_{1}$ and $x_{n}$ are the start and the end values of the independent variables during the time-series, respectively.

\subsubsection{Detection of trend-shift features}

The trend-shift feature is a nonlinear feature, which can be detected by time-series breakpoints analysis method. A trend-shift was determined only when statistical structural changes occurred in the time-series datasets. In this study, we used BFAST method to detect the trend-shift features in the monthly precipitation series and monthly mean temperature series based on the BFAST package in R software (R Core Team, 2017). BFAST is a multiple breakpoint detection method based on the trend-seasonal decomposition method and structural change tests, which is developed from econometric models (Zeileis et al., 2001, 2005; Zeileis, 2005). It has been successfully used to detect trend and seasonal structural changes in the normalized difference vegetation index timeseries datasets (Verbesselt et al., 2010a, b) and has been proved to be a powerful method to detect structural changes in time-series models. The method has been proved less sensitive to cyclical changes in time-series (Verbesselt et al., 2010a; Jong et al., 2013). BFAST used iterative strategies to gradually find the breakpoints based on a trend-seasonal decomposition model and structural change detection model (Zeileis et al., 2001, 2005; Zeileis, 2005; Jong et al., 2013). The final output model was determined by a best-fit model, i.e., the Bayesian information criterion (BIC). The results of BFAST do not only reflect whether the trajectory has the trend-shift features or not, but also the confidence interval and mutation date if the trend-shift really does occur. In this study, the significance level was $95 \%(\alpha=0.05)$.

The BFAST method is different from traditional decomposition methods, such as seasonal-trend decomposition based on locally weighted regression (STL), which is only applicable to a timeseries without continuous breaking signals (Cleveland and Cleveland, 1990). The BFAST method used an initial seasonal model resulting from STL to start the model as in Equation 7, and then replaced the piecewise trend and seasonal models through iteration. The iteration continues until the number and location of breakpoints does not change in the next iteration.

$$
y_{t}=a_{1}+a_{2} t+\sum_{j=1}^{k} r_{j} \sin \left(\frac{2 \pi j t}{f}+\delta_{j}\right)+\varepsilon_{t},
$$

where $y_{t}$ is the time-series observations; $a_{1}$ is the intercept; $a_{2}$ is the slope of the trend; $r_{j}$ is the amplitude; $\delta_{j}$ is the phase (i.e., season); $k$ is the harmonic terms; $f$ is the frequency (e.g., $f=12$ in the 
monthly precipitation series and monthly mean temperature series); and $\varepsilon_{t}$ is the unobservable error at time $t$, i.e., standard deviation $(\sigma)$.

The piecewise trend or seasonal model in BFAST was formed using the structural change detection model after Equation 7 and was rewritten as Equations 8-10:

$$
\begin{gathered}
y_{\mathrm{t}}=x_{t}^{\mathrm{T}} \beta+\varepsilon_{t}, \\
x_{t}=\{1, t, \sin (2 \pi 1 t / f), \cos (2 \pi 1 t / f), \ldots, \sin (2 \pi k t / f), \cos (2 \pi k t / f)\}^{\mathrm{T}}, \\
\beta=\left\{a_{1}, a_{1}, r_{1} \cos \delta_{1}, r_{1} \sin \delta_{1}, \ldots, r_{k} \cos \delta_{k}, r_{k} \sin \delta_{k}\right\}^{\mathrm{T}},
\end{gathered}
$$

where $x_{t}$ and $\beta$ are the independent variable and the regression coefficient in the standard linear regression model, respectively.

The moving sums (MOSUM) of the ordinary least squares (OLS) residuals process (OLSMOSUM), a generalized fluctuation test (Zeileis et al., 2001, 2005; Zeileis, 2005), was used to determine the breakpoints of structural change. The regression parameter $\beta$ can be estimated and tested by the least-squares estimation. The OLS-MOSUM process is the sum of a fixed number of residuals in a temporal window whose size is determined by the bandwidth parameter. The window moves over the whole time-series and the OLS-MOSUM process is defined as Equation 11:

$$
\mathrm{MO}_{t}=\frac{1}{\hat{\sigma} \sqrt{n}} \sum_{s=t-h+1}^{t}\left(y_{s}-x_{s}^{\mathrm{T}} \hat{\beta}\right)
$$

where $\mathrm{MO}_{t}$ is the OLS-MOSUM process; $\hat{\beta}$ is the estimated parameter $\beta$ from a stable historical period $t=1, \ldots, n$; and $h$ is the bandwidth of MOSUM $(h \in(0,1))$. The parameter $h$ in BFAST was set to 0.18 , which indicated that we limited the minimum interval between two breakpoint years to about 120 months, i.e., 10 years. This predetermined value of $h$ corresponded to several climate change studies which concerned changes on a decade scale.

The hypothesis of structural change detection is that the value of $\mathrm{MO}_{t}$ should be close to 0 and only fluctuates randomly during the window's movement if there is no trend-shift in the time-series. Once the trend-shift appears when the window is moving, the value of $\mathrm{MO}_{t}$ will systematically deviate from 0 . The trend-shift is determined when the absolute value of $\mathrm{MO}_{t}$ exceeds a boundary that is asymptotically only crossed with a $5 \%$ probability under structural stability (Verbesselt et al., 2012).

The BIC was used to select the best-fit model once all the possible models with different breakpoints had been set up in the previous two models. The BIC is calculated as in Equation 12:

$$
\mathrm{BIC}=-2 \ln (L)+k,
$$

where $L$ is the maximum likelihood of the model; and $k$ is the number of parameters. We selected the model with the minimum value of BIC. The optimum number and position of the mutation points occur when the BIC minimum is satisfied. At this time, the overall equation-fitting residual and the model complexity achieve the best balance (Bai and Perron, 2003; Verbesselt et al., 2010a, b).

\section{Results}

\subsection{Trend features in Inner Mongolia}

\subsubsection{Trend features on a regional scale}

Figure 2 shows the trend features of the annual mean temperature series and annual precipitation series on a regional scale in the study area during 1962-2015. The annual mean temperature series increased significantly, with a change rate of $56.2 \%$ and an increase in magnitude of $0.4^{\circ} \mathrm{C}$ per decade $(\alpha=0.05)$. During the same period, the annual precipitation series increased slightly, with a change rate of $1.7 \%$ and an increase in magnitude of $0.07 \mathrm{~mm}$ per decade. However, the positive trend in the annual precipitation series was not statistically significant $(\alpha=0.05)$. The results indicated that, on the regional scale, although annual precipitation remains relatively low with 
insignificant increases, the study area becomes warmer-wetter with temperature continually increasing during 1962-2015.

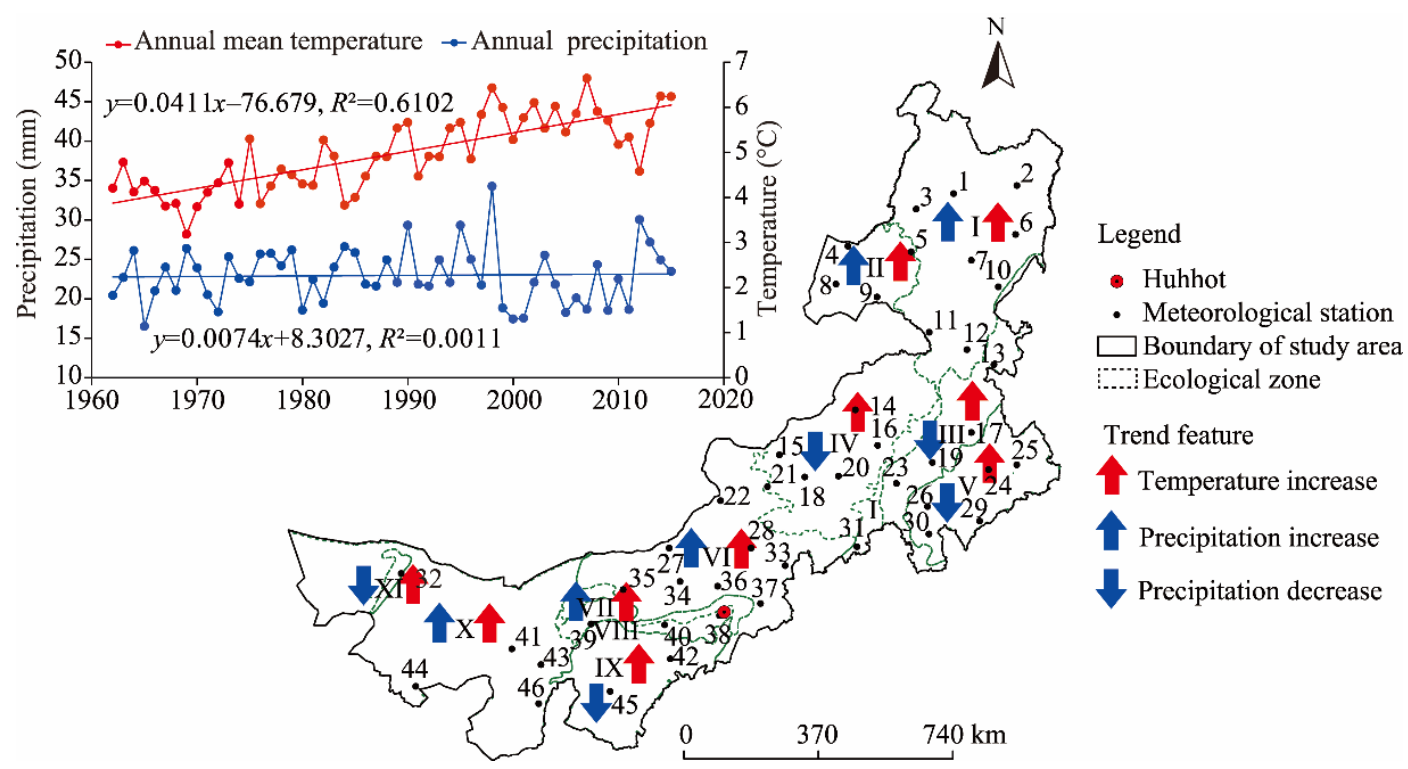

Fig. 2 Trend feature of the annual precipitation series and annual mean temperature series on a regional scale (left-top) and in different ecological zones from 1962 to 2015

The anomaly analysis further showed that the lasting positive trend in the annual mean temperature series (Fig. 3) was contributed by the negative anomalies in 1962-1992 and the positive anomalies in 1993-2015 (Fig. 3). The coldest year was in 1969, with an annual mean temperature of only $3.2^{\circ} \mathrm{C}$, while the warmest year was in 2007 , with the annual mean temperature of $6.6^{\circ} \mathrm{C}$. The coefficient of variations in the annual mean temperature series was $21.0 \%$, which was higher than that in the annual precipitation series (14.9\%). During the same period, although the overall trend in the annual precipitation series changed slowly and slightly $(1.7 \%)$, there was strong inter-annual variations, with a coefficient of variations up to $14.9 \%$. The wettest year was in 1998, with an annual precipitation of $32.3 \mathrm{~mm}$ and a percentage precipitation anomaly increasing to $50.9 \%$, while the driest year was in 1965 , with an annual precipitation of only $16.5 \mathrm{~mm}$.
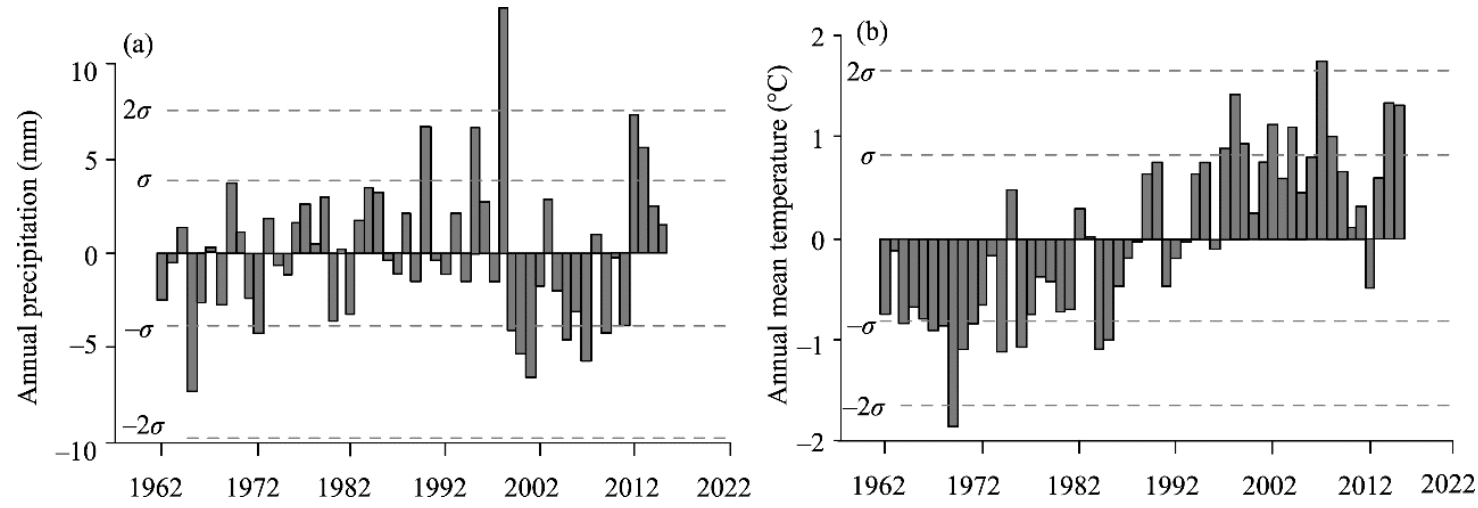

Fig. 3 Anomaly analysis of the annual precipitation series (a) and annual mean temperature series (b) on a regional scale from 1962 to 2015 . The gray dotted lines in each bar chart denote a deviation from the mean value for the period.

\subsubsection{Trend features in different ecological zones}

Although there was a warmer-wetter trend feature on a regional scale, the results were varied when we analyzed the trend features of the annual precipitation series and annual mean temperature series 
in different ecological zones. Not all the ecological zones followed the same warmer-wetter trend as the overall regional feature (Fig. 2; Table 2).

Trend features of the annual mean temperature series in each ecological zone and meteorological station showed a statistically significant warmer trend. But the change rates of the annual mean temperature series in different ecological zones and meteorological stations had a strong spatial heterogeneity. Specifically, the meteorological stations 39 in Yinshan Mountains in the zone of VII, 38 on Hetao-Tumochuan Plain in VIII, and 42 in the Ordos Plateau in the zone of IX, were the top three stations with the highest increasing rates in temperature with the increases of $0.56^{\circ} \mathrm{C}, 0.51^{\circ} \mathrm{C}$ and $0.52^{\circ} \mathrm{C}$ per decade, respectively. Meanwhile, meteorological stations 29,30 and 26 in West Liaohe Plain in the zone of V had the lowest increasing rates, with the increases of $0.15^{\circ} \mathrm{C}, 0.22^{\circ} \mathrm{C}$ and $0.26^{\circ} \mathrm{C}$ per decade, respectively. Therefore, temperature increase was mainly concentrated in the southwestern (VII, VIII and IX) and southeastern (V) Inner Mongolia.

Trend change of the annual precipitation series in different ecological zones and meteorological stations also had an obvious spatial heterogeneity. Moreover, some of them even showed an absolute opposite change trend. The zones of I, II, VI, VII, VIII and X had 29 meteorological stations distributed in the northeastern and northwestern Inner Mongolia. The trend features of the annual precipitation series showed the same wetter trend as that at the regional scale. Meteorological stations 2, 10 and 6 in the zone of I were the top three stations, with the highest increasing rates in annual precipitation, with the increases of 4.93, 1.17 and $1.14 \mathrm{~mm}$ per decade, respectively. Meanwhile, the zones of III, IV, V, IX and XI, with 17 meteorological stations, showed drier trends during 1962-2015. These regions are mainly located in the central and southern Inner Mongolia, especially in the southeastern and southwestern areas. Meteorological stations 26, 29 and 25 in West Liaohe River Plain in the zone of $\mathrm{V}$ had the highest decreasing rates in annual precipitation, with the decreases of $1.20,0.95$ and $0.70 \mathrm{~mm}$ per decade, respectively.

Trend analyses of the annual mean temperature series and annual precipitation series on an ecological zone scale indicated that 6 of the 11 ecological zones had the warmer-wetter trend as at the regional scale. The other 5 ecological zones went through a warmer-drier trend, within which the zones of V and IX were the typical hotspot areas.

Table 2 Trend features of the annual precipitation series and annual mean temperature series in different ecological zones

\begin{tabular}{ccccc}
\hline \multirow{2}{*}{$\begin{array}{c}\text { Ecological } \\
\text { zone }\end{array}$} & Changes of annual precipitation series per decade & & Changes of annual mean temperature series per decade \\
\cline { 2 - 3 } I & $(\%)$ & 0.76 & $(\%)$ & 0.36 \\
\hline II & 11.38 & 0.11 & 153.62 & 0.36 \\
III & 2.37 & -0.03 & 177.35 & 0.39 \\
IV & -0.46 & -0.02 & 46.58 & 0.41 \\
V & -0.41 & -0.66 & 406.10 & 0.27 \\
VI & -11.21 & 0.05 & 23.66 & 0.42 \\
VII, VIII & 1.40 & 0.28 & 72.62 & 0.50 \\
IX & 6.66 & -0.02 & 45.17 & 0.45 \\
X & -0.47 & 0.36 & 44.15 & 0.37 \\
XI & 19.09 & -0.10 & 26.67 & 0.49 \\
Inner & -18.34 & 0.07 & 34.17 & 0.40 \\
Mongolia & 1.72 & & 56.16 & \\
\hline
\end{tabular}

\subsubsection{Seasonal trend features}

Seasonal trend features were also analyzed to discover more details in the changes of temperature series and precipitation series from 1962 to 2015 (Fig. 4). Figures 4e-f demonstrated that the positive trend in the regional seasonal accumulated temperature series was contributed by the statistically significant positive trend in every season. Temperature in the vegetation's non-growing season (October to April) was found to increase more dramatically than in the growing season (May to September), in the order of winter $>$ spring $>$ autumn $>$ summer. 

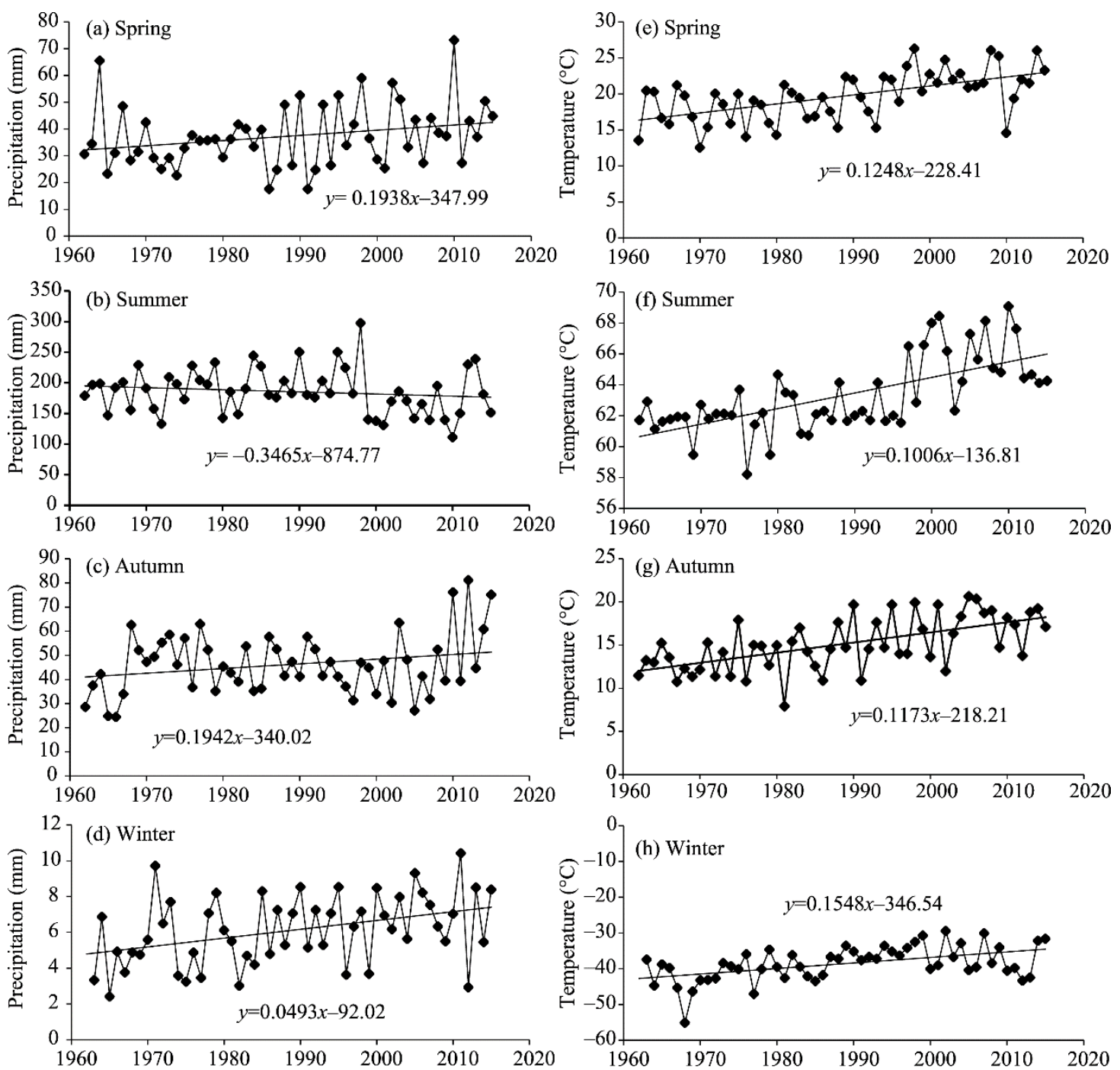

Fig. 4 Seasonal trend features of regional accumulated precipitation series (a-d) and seasonal accumulated temperature series (e-f) series in different seasons during 1962-2015

The seasonal accumulated precipitation series showed obvious positive trends in spring, autumn and winter (autumn $>$ spring $>$ winter) (Figs. 4a, c and d). However, the seasonal accumulated precipitation series in summer decreased slightly (Fig. 4b). In Inner Mongolia, summer precipitation accounts for $60 \%-70 \%$ of the annual amount according to our datasets and a previous study (Zhao et al., 2012). The increased precipitation in autumn, spring and winter was offset by the decreased amount in summer, so that the annual increase was non-significant. Seasonal trend feature analysis in precipitation series and temperature series showed that the study area went through a warmer-drier summer and warmer-wetter spring, autumn and winter during 1962-2015.

\subsection{Trend-shift features in Inner Mongolia}

\subsubsection{Trend-shift features on a regional scale}

Results of trend-shift detection in the monthly mean temperature series and monthly precipitation series on a regional scale are shown in Figure 5. The monthly mean temperature series showed an increasing trend without a statistically significant periodical trend-shift, while the monthly precipitation series had an obvious trend-shift pattern. The structural breakpoint was identified being in April 1999 (i.e., Time of BP(s) 448; Fig. 5) in the precipitation series, which separated the whole series into two sub-periods $(\alpha=0.05)$. The trend change rates in the first and second sub- 
periods were about $22.5 \%$ and $41.6 \%$, respectively. The trend in the second sub-period were dramatically higher than in the first sub-period followed by a statistically significant drop in precipitation in the year 1999. This indicates that the warmer-wetter climate trend in Inner Mongolia was accelerated by the significantly increased trend-shift of the monthly precipitation series after the year 2000 .
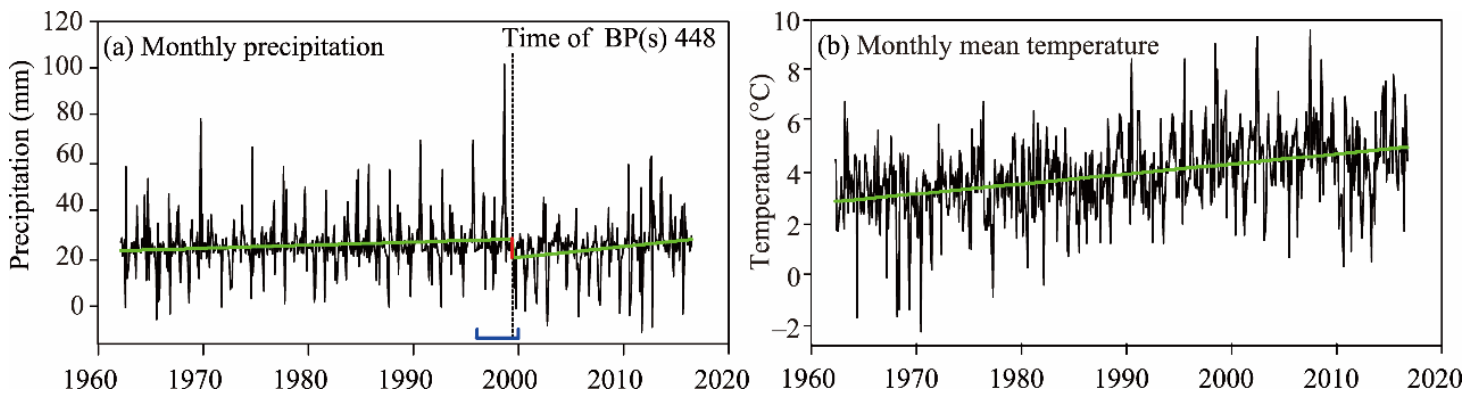

Fig. 5 Trend-shift features in the monthly precipitation series (a) and monthly mean temperature series (b) from 1962 to 2016. Green lines denote piecewise trends during the study period, the red line denotes the magnitude of the structural breakpoints, and the blue line represents the confidence interval of the detected breakpoints. Time of $\mathrm{BP}(\mathrm{s}) 448$ means the $448^{\text {th }}$ point in the time series is detected to be the break point.

\subsubsection{Trend-shift features in different ecological zones}

Although the regional monthly mean temperature series did not have a statistically significant trend-shift feature, there are trend-shift patterns in monthly mean temperature from different ecological zones. Table 3 shows that the zones of VII, VIII and IX had significant trend-shift features in 1996. It seems that the local trend-shift signals in these three zones were weakened or concealed after averaging the change in the other regions. The three neighboring zones were concentrated in the southwestern Inner Mongolia. However, the trend-shift pattern in Figure 6 further indicates that the positive trend of the monthly mean temperature series slowed down after a temporary positive jump in 1996.

Although the regional monthly precipitation series indicated a significant trend-shift in 1999, not all the ecological zones had the same change signals. It showed that only the monthly precipitation series in the zones of I and II went through the same significant trend-shift pattern in 1999 (Table 3). Therefore, zone I and its neighboring zone II, located in northern Inner Mongolia, were typical trendshift areas because all the other areas of Inner Mongolia indicated no significant trend-shift. The same shift signals of the monthly precipitation series in the zones of I and II and in the whole study area indicated that the trend-shift in the whole study area was likely induced by the trend-shift that happened in northern Inner Mongolia during the past 54 years. Besides, it was noticeable that although zone I had a high increase in trend (Table 2), the positive trend of the monthly precipitation series in region I significantly increased since 1999 after a temporary negative jump (Fig. 6).

(a) Monthly precipitation_zone I no. iterations to estimate breakpoints: 3

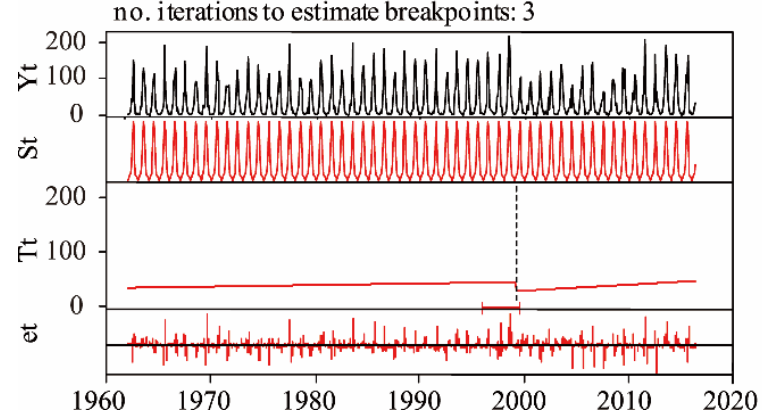

(b) Monthly mean temperature_zone VII \& VIII

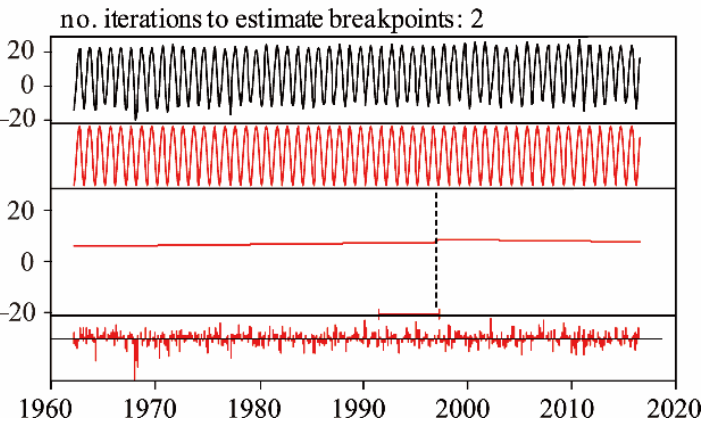

Fig. 6 Trend-shift of monthly precipitation series in zone I (a) and monthly mean temperature series in the zones of VII and VIII (b). Yt, the original time-series datasets; St, the seasonal component; Tt, the trend component; and et, the residual component. 
Table 3 Trend-shift features in different ecological zones

\begin{tabular}{ccc}
\hline Ecological zone & Monthly precipitation series & Monthly mean temperature series \\
\hline I & $1999 \uparrow-\uparrow$ & - \\
II & $1999 \uparrow-\uparrow$ & - \\
III & - & - \\
IV & - & - \\
V & - & - \\
VI & - & $1996 \uparrow+\uparrow$ \\
VII, VIII & - & $1996 \uparrow+\uparrow$ \\
IX & - & - \\
X & - & \\
\hline
\end{tabular}

Notes: - means that there is no significant trend-shift feature; 1999 and 1996 refer to the detected breakpoint years; $\uparrow$ and $\downarrow$ mean positive and negative trends of a sub-period segmented by the breakpoint, respectively; - and + mean negative and positive jump directions in the breakpoint years, respectively.

Therefore, the period 1996-1999 was a key period because the accelerated increase of the monthly precipitation series and alleviated increase of the monthly mean temperature series occurred simultaneously after the key period (Fig. 6). The results showed that the temperature and precipitation in these key years controlled or contributed to the spatio-temporal change pattern in local zones (I, II, VII, VIII and IX).

\section{Discussion}

\subsection{Change features in Inner Mongolia}

Regional trend change features indicated that there was a warmer-wetter trend the study area during 1962-2016. The positive trend in the annual mean temperature series was contributed to by the same positive trend found in each season (winter $>$ spring $>$ autumn $>$ summer), while the positive trend in the annual precipitation series was contributed by the negative trend of the summer accumulated precipitation series and the positive trend of the other three seasons (autumn>spring $>$ winter). After the year 2000, the warmer-wetter trend of climate in Inner Mongolia was accelerated. The results reveal unique climate change characteristics in Inner Mongolia compared with the other areas.

The regional annual mean temperature series had a significantly positive trend, with an increase in magnitude of $0.40^{\circ} \mathrm{C}$ per decade, which was close to the results of $\mathrm{Hu}$ et al. (2015). However, it was obviously higher than the global warming rate of $0.14^{\circ} \mathrm{C}$ per decade and the warming rate of $0.37^{\circ} \mathrm{C}$ per decade in the Tibetan Plateau (Yang et al., 2014), which is another unique arid area in China. This indicated that the arid/semi-arid area experienced a more accelerated warming trend than other areas around the world, with trend features possessing strong spatial heterogeneity in the world's different arid/semi-arid areas. The conclusion that temperature in winter increased faster than in summer was consistent with previous studies (Borjigin, 2015), and February was found to have the strongest temperature increasing trend in a previous study (Hu et al., 2015). Although we did not find a trend-shift change in the regional monthly mean temperature series, we did find it in the local monthly mean temperature series, in 1996 around Ordos Plateau (zone IX), Yinshan Mountains (zone VII) and Hetao-Tumochuan Plain (zone VIII). The change pattern in these areas corresponded to the previous conclusions that the increasing trend in global temperature has slowed down since the late 1990s (Hu et al., 2017).

With regard to the change in the regional annual precipitation series, although the overall trend in the annual precipitation series changed slowly and slightly with a change rate of $1.7 \%$, there was a strong inter-annual variation, with a coefficient of variation up to $14.9 \%$. Because the precipitation series had a strong inter-annual variation, with a relatively continuous dry period from 2000 to 2010, several studies based on precipitation data prior to 2010 resulted in a decreasing trend in the precipitation series (Hu et al., 2015), which was also proven by our analysis. The strong inter-annual variation in the annual precipitation series might be the reason for contrary results in 
previous studies based on different study periods. The negative trend in the summer accumulated precipitation series was also confirmed by other studies in Inner Mongolia (Geng et al., 2016; Hu et al., 2017), and this feature was consistent across the whole Mongolian Plateau in northeastern Asia (Qin et al., 2018). We further analyzed the regional summer accumulated precipitation series and the results showed no trend-shift features. The detected trend-shift features in the regional precipitation series were consistent with previous results indicated by observing the time-series change trajectory (Hu et al., 2017).

The spatio-temporal heterogeneity of the temperature series and precipitation series begs more careful attention. After the late $20^{\text {th }}$ century, the warmer-wetter trend of climate in Inner Mongolia accelerated. However, the West Liaohe River Plain (zone V) and Ordos Plateau (zone IX), located in the southeastern and southwestern Inner Mongolia, respectively, went through a warmer-drier trend different from that in other zones. More attention should be paid to water management for sustainable development of the environment in areas with more fragile ecosystems, such as the Horqin Sandy Land in the north part of zone V and the Mu Us Sandy Land in zone IX. In other pastoral areas, such as the Xilingol Plateau, although the precipitation decreased slightly, the obvious and dramatic temperature increase might have accelerated regional evaporation and somehow influenced the typical, widely distributed, warm-temperate steppe. In some traditional agricultural areas, such as the southern zone $\mathrm{V}$, the decreased precipitation may have decreased the precipitation-related corn yield.

\subsection{Importance of capturing nonlinear climate change}

The nonlinear change pattern of climate variables on regional and ecological zone scales was an important piece of data for many scientific studies focusing on arid/semi-arid areas. The trend change feature can only indicate an overall change direction of the climate variables, while capturing nonlinear climate change can profile more details hidden in an apparently consistent trend line.

The arid index (Huang et al., 2016) and the standardized precipitation evapotranspiration index (Yao et al., 2018) can describe and differentiate the evolution of arid and semi-arid ecosystems. Precipitation and temperature are the key parameters, and nonlinear trend-shift features in the monthly precipitation series and monthly mean temperature series may influence the values calculated using these indices in some specific years, or even the overall trend. Besides, the coupled and response relationship between climate drivers and arid/semi-arid ecosystems may change because of the trend-shift features hiding in the monthly mean temperature series and monthly precipitation series. Our results indicated that the regional precipitation-vegetation relationship may change after the structural break year of the precipitation series. Trend-shift features in precipitation may provide a new perspective for studies on arid ecological resilience, which focus on the nonlinear dynamics observed in arid ecosystems (Holling, 1973; Wu et al., 2017).

Trend-shift change features in the monthly precipitation series and monthly mean temperature series are also important for earth-atmosphere system models. The complicated interaction between climate, human activity and vegetation is critical for almost all studies based on earth-system models. Nonlinear changes in climate factors may influence the reliability of some models because they assume the stability of the climate-vegetation relationship. For example, in the residual trends model (Li et al., 2012; Xu et al., 2018), which is designed for discriminating between different drivers of land cover change, ignoring the trend-shift of time-series, climate variables may result in an overestimation or underestimation of the contribution of climate when discriminating between human-induced and climate-induced vegetation changes.

\subsection{Limitations and further research}

This paper detected trend and trend-shift change features in the temperature series and precipitation series without analyzing the reasons for the changes. Why these changes happened, however, is also an important and interesting scientific problem. We believe that many factors may together influence the change results, such as the changes in other climate variables, interaction between regional temperature and regional precipitation, interaction between regional human activity and 
arid/semi-arid environment and atmospheric circulation on a continental or global scale. Further studies could focus on this fields when there are more related datasets available.

We only used publicly available climate datasets from 46 meteorological stations. We believe that data from more dense meteorological stations may add further detail to our results. To do more specific research, further study could use more meteorological stations, or some publicly available gridded climate datasets, such as version 4 of the moderate resolution imaging spectroradiometer land surface temperature dataset, or gridded climate datasets released by Yang et al. (2014).

As discussed in Section 4.2, the nonlinear interaction between climate factors and arid/semi-arid vegetation is an important topic. This paper did detect the nonlinear changes in climate factors but it did not further analyze how they influenced the change in vegetation and whether there was a nonlinear relationship between climate factors and arid/semi-arid vegetation. This was because the temporal accumulation of the regional vegetation dataset, i.e., remote sensing vegetation index (NDVI) or enhanced vegetation index, was not long enough to match the temporal accumulation of meteorological data in this study. However, the results from this paper provide important background information for further studies on the nonlinear relationship between climate and vegetation in arid/semi-arid areas. We believe that multivariate time-series nonlinear models and nonlinear system stability analysis methods, such as phase space analysis, may have the potential to aid further study of this issue.

\section{Conclusions}

This study took Inner Mongolia of China as a study area, initially using a simple linear trend detection method to detect trend features in the annual mean temperature series and annual precipitation series and then the BFAST method to detect trend-shift features in those series. The results were as follows: (1) A warmer-wetter trend was shown during the past 54 years from 1962 to 2015 . The regional annual mean temperature series increased $0.4^{\circ} \mathrm{C}$ per decade with a change rate of $56.2 \%$. The regional annual precipitation series slightly increased $0.07 \mathrm{~mm}$ per decade with change rate of about $1.7 \%$, but the trend was not statistically significant. (2) The wammer trend was attributed to the same positive trend in each season (winter $>$ spring $>$ autumn $>$ summer), while the wetter trend was contributed by the negative trend of the summer precipitation and the positive trend of the other three seasons (autumn $>$ spring $>$ winter). It showed the study area went through a warmer-drier summer, and at the same time a warmer-wetter spring, autumn and winter. (3) The monthly precipitation series had a trend-shift pattern with a structural breakpoint in 1999 separating the whole series into two sub-periods. The trend change in the second period was dramatically higher than in the first period followed by an obvious drop in precipitation in 1999. The monthly mean temperature series showed an increased trend without periodical trend changes. Therefore, the warmer-wetter trend of climate in Inner Mongolia accelerated after the year 2000. (4) Local zones went through a warmer-drier trend compared with other areas, such as zone V and IX. The late $20^{\text {th }}$ century was a key period because the acceleration of the wetter trend in zones I and II, and the alleviation of the warmer trend in zones VII, VIII and IX, occurred simultaneously.

The result is important for analyzing arid/semi-arid climate change, elucidating the interaction mechanisms between climate and arid/semi-arid ecosystems, illuminating other arid-ecosystem processes and augmenting prediction studies based on earth-system models. Further studies could focus on the change reasons and use more meteorological stations or some publicly available gridded climate datasets to do more specific research. Multivariate time-series nonlinear models and nonlinear system stability analysis methods, such as phase space analysis, may be used to specify the nonlinear relationship between climate factors and arid/semi-arid vegetation.

\section{Acknowledgements}

This study was supported by the National Natural Science Foundation of China (41701474, 41701467), the National Key Research and Development Plan of China (2016YFC0500205), the National Basic Research Program of China (2015CB954103) and the Key Laboratory for National Geograophy State Monitoring (National Administration of 
Surveying, Mapping and Geoinformation; 2017NGCM09). The authors are grateful to the anonymous reviewers for their constructive criticism and comments.

\section{References}

An L J. 2015. Variations in autumn temperature in Inner Mongolia and circulation characteristics of abnormal low temperature types during 1961-2012. Desert and Oasis Meteorology, 9(6): 34-39. (in Chinese)

Bai J, Perron P. 2003. Computation and analysis of multiple structural change models. Journal of Applied Econometrics, 18(1): $1-22$.

Bao Y, Li X B, Li C. 2010. Spatial-temporal distribution characteristics of temperature in Inner Mongolia during 1961-2007. Journal of Arid Land Resources and Environment, 24(12): 80-84. (in Chinese)

Bhandari J, Pan X, Bijaya G C D. 2015. Spatial and seasonal variation in rain use efficiency in semiarid grasslands of Inner Mongolia. Advances in Meteorology, 917415, doi:10.1155/2015/917415.

Charles J. 2012. Global weirdness: severe storms, deadly heat waves, relentless drought, rising seas, and the weather of the future. Reports of the National Center for Science Education, 33(4): 6.

Chen H, Shao L, Zhao M, et al. 2017. Grassland conservation programs, vegetation rehabilitation and spatial dependency in Inner Mongolia, China. Land Use Policy, 64: 429-439.

Chen X, Li B L, LI Q, et al. 2012. Spatio-temporal pattern and changes of evapotranspiration in arid Central Asia and Xinjiang of China. Journal of Arid Land, 4(1): 105-112.

Chen Z, Zhang X, He X, et al. 2013. Extension of summer (June-August) temperature records for northern Inner Mongolia (1715-2008), China using tree rings. Quaternary International, 283(2): 21-29.

Cleveland R B, Cleveland W S, McRae J E, et al. 1990. STL: A seasonal-trend decomposition procedure based on loess. Journal of Official Statistics, 6(1): 3-33.

Dufresne J L, Foujols M A, Denvil S, et al. 2013. Climate change projections using the IPSL-CM5 earth system model: from CMIP3 to CMIP5. Climate Dynamics, 40(9-10): 2123-2165.

Fisher R A, Koven C D, Anderegg W, et al. 2017. Vegetation demographics in earth system models: a review of progress and priorities. Global Change Biology, 24(1): 35-54.

Geng Q, Wu P, Zhao X. 2016. Spatial and temporal trends in climatic variables in arid areas of Northwest China. International Journal of Climatology, 36(12): 4118-4129.

Guo L, Wu S, Zhao D, et al. 2014. NDVI-Based vegetation change in Inner Mongolia from 1982 to 2006 and its relationship to climate at the biome scale. Advances in Meteorology, 2014: 79-92.

Han F, Zang Q, Buyantuev A, et al. 2015. Effects of climate change on phenology and primary productivity in the desert steppe of Inner Mongolia. Journal of Arid Land, 7(2): 251-263.

Harrison S P, Laforgia M L, Latimer A M. 2018. Climate-driven diversity change in annual grasslands: drought plus deluge does not equal normal. Global Change Biology, 24(4): 1782-1792.

Hartmann D L, Klein Tank, A M G, Rusticucci M, et al. 2013: Observations: Atmosphere and Surface. In: Qin T F, Plattner D, Tignor M, et al. Climate Change 2013-The Physical Science Basis. Cambridge: Cambridge University Press. 159-254

Holling C S. 1973. Resilience and stability of ecological systems. Annual Review of Ecology and Systematics, 4(4): 1-23.

Hu Q, Pan F, Pan X, et al. 2015. Spatial analysis of climate change in Inner Mongolia during 1961-2012, China. Applied Geography, 60: 254-260.

Hu Y, Wang S, Song X, et al. 2017. Precipitation changes in the mid-latitudes of the Chinese mainland during 1960-2014. Journal of Arid Land, 9(6): 924-937.

Huang J, Xue Y, Sun S, et al. 2015a. Spatial and temporal variability of drought during 1960-2012 in Inner Mongolia, North China. Quaternary International, 355: 134-144.

Huang J, Ji M, Xie Y, et al. 2015b. Global semi-arid climate change over last 60 years. Climate Dynamics, 46(3-4): 1131-1150.

Huang J, Yu H, Guan X, et al. 2016. Accelerated dryland expansion under climate change. Nature Climate Change, 6(2): 166172.

Huang J, Yu H, Dai A, et al. 2017. Drylands face potential threat under $2{ }^{\circ} \mathrm{C}$ global warming target. Nature Climate Change, $7(6)$ : 417-422.

Jong R D, Verbesselt J, Zeileis A, et al. 2013. Shifts in global vegetation activity trends. Remote Sensing, 5(3): 1117-1133.

Leng G, Tang Q, Rayburg S. 2015. Climate change impacts on meteorological, agricultural and hydrological droughts in China. Global and Planetary Change, 126(126): 23-34.

Li A, Wu J, Huang J. 2012. Distinguishing between human-induced and climate-driven vegetation changes: a critical application 
of RESTREND in Inner Mongolia. Landscape Ecology, 27(7): 969-982.

Liu Q S, Liu G H, Huang C. 2018. Monitoring desertification processes in Mongolian Plateau using MODIS tasseled cap transformation and TGSI time series. Journal of Arid Land, 10(1): 12-26.

Maestre F T, Cortina J. 2002. Spatial patterns of surface soil properties and vegetation in a Mediterranean semi-arid steppe. Plant and Soil, 241(2): 279-291.

Mahoney J R, Patrinos A, Schafer J, et al. 2004. Strategic plan for the U.S. climate change science program climate change: science program and the subcommittee on global change research. Environmental Policy Collection, 74(4): 1-6.

Mora C, Dousset B, Caldwell I R, et al. 2017. Global risk of deadly heat. Nature Climate Change, 7(7): 501-506.

Peng S, Piao S, Shen Z, et al. 2013. Precipitation amount, seasonality and frequency regulate carbon cycling of a semi-arid grassland ecosystem in Inner Mongolia, China: a modeling analysis. Agricultural and Forest Meteorology, 178-179(4): 46-55. Qin F, Jia G, Yang J, et al. 2018. Spatiotemporal variability of precipitation during 1961-2014 across the Mongolian Plateau. Journal of Mountain Science, 15(5): 992-1005.

R Core Team. 2017. R: A language and environment for statistical computing. R Foundation for Statistical Computing, Vienna, Austria. [2018-02-21]. https://www.R-project.org/.

Shao L, Chen H, Zhang C, et al. 2017. Effects of major grassland conservation programs implemented in Inner Mongolia since 2000 on vegetation restoration and natural and anthropogenic disturbances to their success. Sustainability, 9(3): 466.

Suld B. 2015. Charactersitics of the climate change and the impact on NDVI in Inner Mongolia Grassland. MSc Thesis. Huhhot: Inner Mongolia University. (in Chinese)

Tong S Q, Zhang J Q, Bao Y H, et al. 2017. Spatial and temporal variations of vegetation cover and the relationships with climate factors in Inner Mongolia based on GIMMS NDVI3g data. Journal of Arid Land, 9(3): 394-407.

Verbesselt J, Hyndman R, Zeileis A, et al. 2010a. Phenological change detection while accounting for abrupt and gradual trends in satellite image time series. Remote Sensing of Environment, 114(12): 2970-2980.

Verbesselt J, Hyndman R, Newnham G, et al. 2010b. Detecting trend and seasonal changes in satellite image time series. Remote Sensing of Environment, 114(1): 106-115.

Verbesselt J, Zeileis A, Herold M. 2012. Near real-time disturbance detection using satellite image time series. Remote Sensing of Environment, 123(123): 98-108.

Wang Z, Li J, Lai C, et al. 2017. Does drought in China show a significant decreasing trend from 1961 to 2009?. Science of the Total Environment, 579: 314-324.

Wu J S, Feng Y F, Zhang X Z, et al. 2017. Grazing exclusion by fencing non-linearly restored the degraded alpine grasslands on the Tibetan Plateau. Scientific Reports, 7: 15202

Xu L, Li B, Yuan Y, et al. 2016. Detecting different types of directional land cover changes using MODIS NDVI time series dataset. Remote Sensing, 8(6): 495.

Xu L, Tu Z, Zhou Y, et al. 2018. Profiling human-induced vegetation change in the horqin sandy land of China using time series datasets. Sustainability, 10(4): 1068.

Yang K, Hui W, Jun Q, et al. 2014. Recent climate changes over the Tibetan Plateau and their impacts on energy and water cycle: a review. Global and Planetary Change, 112: 79-91.

Yao J, Zhao Y, Chen Y, et al. 2018. Multi-scale assessments of droughts: a case study in Xinjiang, China. Science of the Total Environment, 630: 444.

You L, Dai X, Zhang Y. 2010. Extreme precipitation events in Inner Mongolia in 1961-2008. Advances in Climate Change Research, 6(6): 411-416.

Zeileis A, Leisch F, Hornik K, et al. 2001. Strucchange: an R package for testing for structural change in linear regression models. Journal of Statistical Software, 7(2): 1-38.

Zeileis A. 2005. A unified approach to structural change tests based on ML scores, F statistics, and OLS residuals. Econometric Reviews, 24(4): 445-466.

Zeileis A, Leisch F, Kleiber C, et al. 2005. Monitoring structural change in dynamic econometric models. Journal of Applied Econometrics, 20(1): 99-121.

Zhang C, Lu D, Chen X, et al. 2016. The spatiotemporal patterns of vegetation coverage and biomass of the temperate deserts in Central Asia and their relationships with climate controls. Remote Sensing of Environment, 175: 271-281.

Zhang L, Karthikeyan R, Bai Z, et al. 2018. Spatial and temporal variability of temperature, precipitation, and streamflow in upper Sang-kan basin, China. Hydrological Processes, 31(2): 279-295.

Zhao Y, Ma M, Li X. 2012. Nutritional value and amino acid content of four grasses in eastern Inner Mongolia. Journal of Animal and Veterinary Advances, 11(21): 3928-3936. 